\title{
Correspondence
}

\section{Brain secrets cheap at twice the price}

The Apollo space missions cost more than US $\$ 100$ billion in today's terms, the Large Hadron Collider $\$ 10$ billion and the development of the Airbus A380 \$15 billion - making the projected $\$ 4.5$ billion for the BRAIN (Brain Research through Advancing Innovative Neurotechnologies) initiative look paltry by comparison (see Nature http://doi.org/tmh; 2014).

If we spent that much putting a man on the Moon, smashing particles and building a flying hotel, why not spend at least $\$ 10$ billion trying to solve the greatest mystery of all? Anuj K. Rastogi University of Toronto, Canada. anuj.rastogi@mail.utoronto.ca

\section{Overcome hurdles to global databases}

We suggest some pointers to guarantee the long-term storage, accessibility and reliability of international research data sets.

Data owners, peer-reviewed journals, research institutes and universities have cited various problems with the feasibility of establishing global databases including maintenance costs, restrictive data-exchange policies and conflicts of interest.

Research organizations need to start implementing management plans for their own data, as is happening at Wageningen University in the Netherlands. Institutional policies, for example, should mandate that researchers store their data in public repositories.

Setting up distributed databases that are owned by the institutions responsible for the data could also extend data sharing. These institutions would develop their own data policy, and could, for example, pinpoint and resolve any conflicts of interest at an early stage.

Funding agencies and all journals should use their

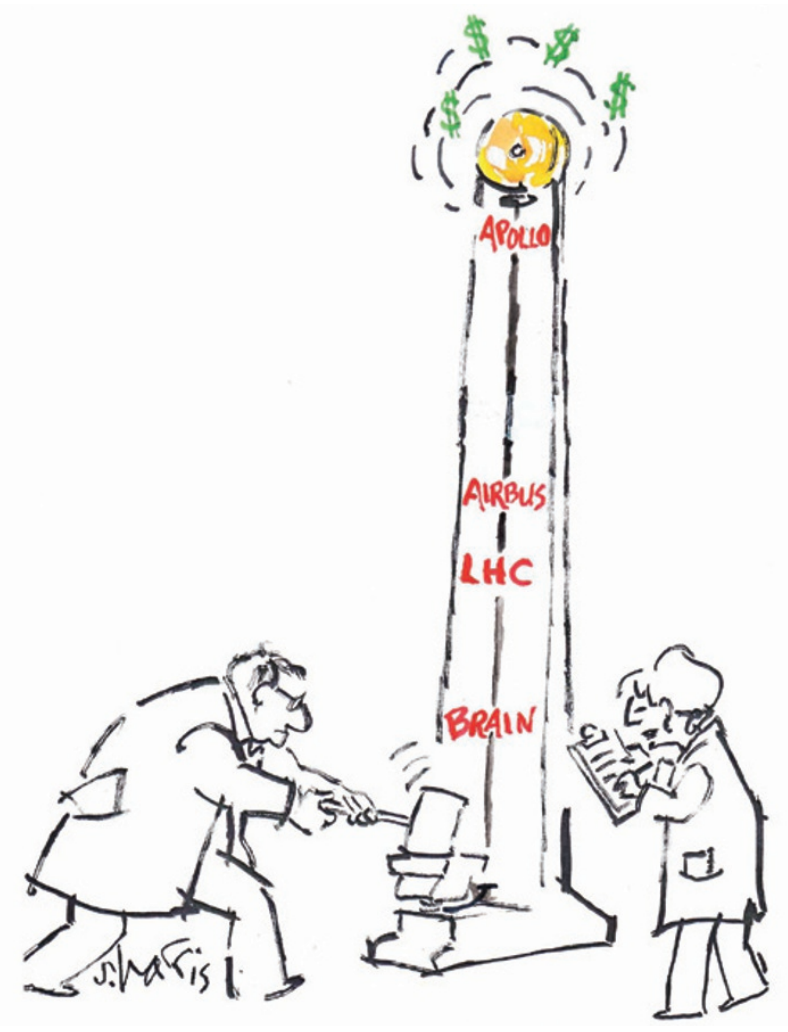

influence to counter restrictive data-sharing policies - for instance, by ensuring that researchers make their data publicly available soon after publication (see, for example, go.nature.com/o5ykhe).

Clear incentives for storing data must replace objections. Collaboration is key to constructing useful databases, both distributed and global. Venceslas Goudiaby, Pieter A. Zuidema, Godefridus M. J. Mohren Wageningen University, the Netherlands.

venceslas.goudiaby@wur.nl

\section{China's land creation project stands firm}

We contest the views of Peiyue Li and colleagues on the geological implications of land creation projects in China, particularly for Yan'an city (see Nature 510, 29-31; 2014).

The Yan'an project has created flat ground by levelling hills and filling valleys, and was carefully planned by the local government after thorough feasibility testing by geoengineers, hydrologists, water conservationists and ecologists. The site was consequently able to withstand severe erosion caused by a oncein-a-century flood in July 2013.

Any threat of collapse of softsoil deposits has been eliminated by repeatedly compacting the relocated soil in layers. This reinforcement strategy has increased soil-particle density from 1.9 to 2.1 grams per cubic centimetre (see go.nature.com/ mqg194; in Chinese).

Guided by strict planning and controls, construction work will initially occur in the excavation area, and will not extend to filled regions until the ground stabilizes through natural sedimentation. The soil interfaces between the excavated and filled areas, slope compaction, and drainage of ground and surface water are also being rigorously monitored.

The newly created land will be used for administrative, residential and commercial purposes, so there will be no risk of industrial pollution. Almost half of the project area will be covered in vegetation.

Yan'an's experience of land creation could be useful for extending other mountain cities in China and abroad.

Yansui Liu, Yuheng Li Beijing Normal University; and Institute of Geographic Sciences and Natural Resources Research, Chinese Academy of Sciences, Beijing, China. liuys@igsnrr.ac.cn

\section{Tactics to stamp out herbicide resistance}

The rise of weeds that are resistant to the herbicide glyphosate has led many US farmers to seek permission from the Environmental Protection Agency to use more-dangerous herbicides, such as propazine (see Nature 510, 187; 2014). To deal with this crisis, US agriculture must implement a multi-pronged strategy.

Tactics should include: annual switching between herbicides that have different chemical modes of action; using a variety of methods to remove weed seeds from the soil, including hoeing by hand; and moving to new tillage practices that require a shift from no-till to rotary hoeing and between-row cultivation of the soil to uproot weeds.

US policy-makers need to encourage crop rotation through new subsidies and to impose restrictions on herbicide use. It seems that Europe has dodged a bullet by resisting pressure to sow glyphosate-tolerant crops. Margaret Mellon Mellon Associates, Washington DC, USA. mardimellon@mac.com

\section{CORRECTION}

The Outlook article 'Fat chance' (Nature 511, S14-S15; 2014) incorrectly stated that ice cream is part of a ketogenic diet. In fact, this diet is high in fat but low in carbohydrate so does not include high-sugar foods. 